\title{
New modified version of the Risk Adjustment for Congenital Heart Surgery category and mortality in premature infants with critical congenital heart disease
}

Young Mi Yoon, MD¹, Seong Phil Bae, MD², Yoon-Joo Kim, MD¹, Jae Gun Kwak, MD, PhD ${ }^{3}$, Woong-Han Kim, MD, PhD ${ }^{3}$, Mi

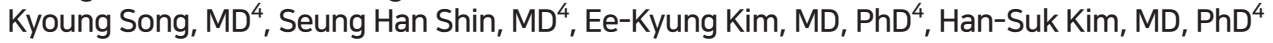

${ }^{1}$ Department of Pediatrics, Jeju National University Hospital, Jeju, Korea; ${ }^{2}$ Department of Pediatrics, Soonchunhyang University Hospital, Seoul, Korea; Departments of ${ }^{3}$ Thoracic and Cardiovascular and ${ }^{4}$ Pediatrics, Seoul National University Hospital Children `s Hospital, Seoul, Korea

Background: Despite advances in neonatal intensive care and surgical procedures, perinatal mortality rates for premature infants with congenital heart disease (CHD) remain relatively high.

Purpose: We aimed to describe the outcomes of premature infants with critical CHD and identify the risk factors including the new modified version of the Risk Adjustment for Congenital Heart Surgery (M-RACHS) category associated with in-hospital mortality in a Korean tertiary center.

Methods: This was a retrospective cohort study of premature infants with critical CHD admitted to the neonatal intensive care unit from January 2005 to December 2016.

Results: A total of 78 premature infants were enrolled. The median gestational age (GA) at birth was 34.9 weeks (range, 26.7-36.9 weeks), and the median birth weight was $1.91 \mathrm{~kg}$ (range, $0.53-4.38 \mathrm{~kg}$ ). Surgical or percutaneous intervention was performed in 68 patients with a median GA at birth of 34.7 weeks (range, 26.7-36.8 weeks) and a median birth weight of $1.92 \mathrm{~kg}$ (range, $0.53-4.38 \mathrm{~kg}$ ). The in-hospital survival rate was $76.9 \%$ among all enrolled preterm infants and $86.8 \%$ among patients who received an intervention. Very low birth weight (VLBW), persistent pulmonary hypertension of the newborn (PPHN), bronchopulmonary dysplasia (BPD), and M-RACHS category 5 or higher (more complex CHD) were independently associated with in-hospital mortality. For the 68 premature infants undergoing cardiac interventions, independent risk factors for mortality were VLBW, BPD, and CHD complexity. Late preterm infant and age at intervention were not associated with patient survival.

Conclusion: For premature infants with critical CHD, VLBW, PPHN, BPD, and M-RACHS category $\geq 5$ were risk factors for mortality. A careful approach to surgical intervention and prenatal care should be taken according to CHD type and neonatal condition.
Key words: Congenital heart disease, Mortality, Outcome, Premature

\section{Key message}

Questions: This study aimed to describe the survival of premature infants with critical congenital heart disease (CHD) and to identify the risk factors including the new modified version of the Risk Adjustment for Congenital Heart Surgery (M-RACHS) associated with mortality.

Finding: For premature infants with critical $\mathrm{CHD}$, survival rate was $76.9 \%$ and very low birth weight (VLBW), persistent pulmonary hypertension of the newborn (PPHN), bronchopulmonary dysplasia (BPD), and M-RACHS 5 or more were associated with in-hospital mortality.

Meaning: VLBW, PPHN and BPD, as well as M-RACHS $\geq 5$, were risk factors for mortality among premature infants with critical CHD.

\section{Introduction}

Preterm births have increased gradually until the last decade, accounting for $5 \%-12 \%$ of births in the US and Europe, ${ }^{1,2)}$ and birth defects are one of the important causes of preterm birth. ${ }^{3)}$ Congenital heart disease (CHD) is the most commonly reported birth defect, with prevalences of 4-50 per 1,000 live births $^{4,5)}$ and 1.7-3 per 1,000 live births for critical CHD. ${ }^{5-7)} \mathrm{A}$ large population-based study from England reported that preterm infants have cardiovascular abnormalities 2 times more frequently than full-term infants. ${ }^{8}$ Unfortunately, these 2 conditions cause significant perinatal and infant morbidity and mortality, ${ }^{4)}$ and premature infants or low birth weight infants with CHD are faced with increased mortality and morbidity. ${ }^{6,8-11)}$

Advances in neonatal intensive care and surgical management

Corresponding author: Mi Kyoung Song, MD. Department of Pediatrics, Seoul National University Children's Hospital, 101 Daehak-ro, Jongno-gu, Seoul 03080, Korea 凶E-mail: mksong52@gmail.com, https://orcid.org/0000-0002-0529-869x 
have contributed to reduce mortality and morbidity in preterm infants with $\mathrm{CHD}{ }^{5,7)}$ However, perinatal mortality in premature infants with $\mathrm{CHD}$ remains relatively high, ${ }^{6,8)}$ and survivors are at risk for short-term morbidity and adverse neurodevelopmental outcomes. ${ }^{6,9,11)}$ The severity of heart defects and category of diseases have also significant impacts on the outcomes of neonates with $\mathrm{CHD},{ }^{4,10,12-14)}$ In a meta-analysis of observational studies, ${ }^{10)}$ the category of cardiac disease was the most important predictor of mortality in low birth weight infants. Therefore, adjustment considering the severity of heart disease should be included in the outcome study of CHD. The Risk Adjustment for Congenital Heart Surgery 1 (RACHS-1) was first designed to allow meaningful comparisons of in-hospital mortality for groups of children undergoing surgery for $\mathrm{CHD}$ relying on variables that are easy to identify and quantify. ${ }^{14)}$ However, because there are many types of $\mathrm{CHD}$ which don't require surgery during neonatal period such as pulmonary stenosis and pink tetralogy of Fallot, modified RACHS (m-RACHS) was suggested and used to estimate adjusted gestational age specific morbidities and mortality in preterm infants with critical CHD. ${ }^{6}$ So far, m-RACHS has not been used to evaluate risk factors for mortality other than gestational age among preterm infants with critical CHD. And there have been no data for the outcome of premature infants with critical CHD in Asian population.

The aim of the present study was to describe the outcomes of premature neonates with critical $\mathrm{CHD}$ and to identify the risk factors including new modified version of the Risk Adjustment for Congenital Heart Surgery category (M-RACHS) associated with in-hospital mortality in a Korean tertiary center.

\section{Methods}

This was a retrospective cohort study performed in a single referral tertiary center. Infants who were born before 37 weeks of gestation with critical $\mathrm{CHD}$ and were admitted within the first month of life to the neonatal intensive care unit of Seoul National University Hospital between January 2005 and December 2016 were included in the study. This study was approved by the Institutional Review Board (IRB) of Seoul National University Hospital (IRB No. 1802-063-921). Informed consent was waived by IRB.

The diagnosis of CHD was made by a pediatric cardiologist according to the echocardiographic findings. Critical $\mathrm{CHD}$ was defined as heart defects requiring surgical intervention or percutaneous intervention with catheterization immediately after birth or within months of life. ${ }^{15)}$ This includes one or a combination of the following defects: complete atrioventricular septal defects, hypoplastic left heart syndrome (HLHS), pulmonary atresia with ventricular septal defect (VSD) or intact ventricular septum, tetralogy of Fallot, transposition of the great arteries, tricuspid atresia, truncus arteriosus, total anomalous pulmonary venous return, coarctation of the aorta, interruption of the aortic arch, double-outlet right ventricle, aortopulmonary window, heterotaxy syndrome and other single-ventricle. In addition, pulmonary and aortic stenosis requiring cardiac intervention before discharge were included as critical CHD. Infants with an isolated atrial septal defect, VSD, or patent ductus arteriosus were excluded from the study. Each patient was classified into 6 severity groups of the M-RACHS to adjust for the complexity of CHD (Table 1). M-RACHS was modified from RACHS-1 and $\mathrm{m}$-RACHS proposed by Steurer et al. ${ }^{6,14)}$ RACHS-1 categorized cardiac surgical procedures for $\mathrm{CHD}$ into 6 risk groups according to similar expected in-hospital mortality rates. The risk category significantly correlated with mortality rate for patients undergoing single cardiac procedure. However, this category is for surgical procedure, not for CHD classification. And m-RACHS by Steurer classified CHD according to complexity with reference to RACHS-1, but aortopulmonary window, complete atrioventricular septal defect, coarctation of aorta with VSD, pulmonary atresia with VSD, and interruption of aortic arch were not included in the m-RACHS classification. So, we further classified these diseases by m-RACHS scoring system and added these CHDs in M-RACHS.

Medical records regarding perinatal factors, including gender, gestational age (GA), birth weight, very low birth weight (VLBW), small for GA (SGA), foetal hydrops, persistent pulmonary hypertension of the newborn (PPHN), and noncardiac structural anomalies or chromosomal abnormalities, were reviewed. Perioperative data, including body weight at intervention, postmenstrual age (PMA) or postnatal age (PNA) at intervention, type of intervention, use of prostaglandin $\mathrm{E} 1$, preintervention $\mathrm{SpO}_{2}$ and ventilator period before intervention, were also reviewed. VLBW was defined as a birth weight $<1,500 \mathrm{~g}$, and SGA was defined as a birth weight $<10$ th percentile according to the Fenton growth chart. ${ }^{16)} \mathrm{PPHN}$ was defined as a mainly right-toleft shunt lesion via a patent ductus arteriosus in patients with biventricular physiology or transposition of the great arteries with a large atrial septal defect requiring inhaled nitric oxide due to severe hypoxemia. ${ }^{17)}$ Clinical outcomes of premature infants, such as sepsis, necrotizing enterocolitis (NEC), intraventricular hemorrhage greater than grade II, periventricular leukomalacia, retinopathy of prematurity, bronchopulmonary dysplasia (BPD), and in-hospital mortality, were collected and analysed. BPD was defined as chronic lung disease requiring supplemental oxygen even after 4 weeks of postnatal age. ${ }^{18)}$ Necrotizing enterocolitis was defined as 2 or more of 3 stages according to the modified Bell's criteria. ${ }^{19)}$ Intraventricular hemorrhage and periventricular leukomalacia were diagnosed by brain ultrasonography perform. ed at intervals of $1-2$ weeks, depending on the patient's condition within 3 days after birth and 7 days after birth.

The study population was divided into the survivor group and the mortality group according to the in-hospital mortality during admission. Categorical variables are expressed as percentages, and continuous variables are expressed as medians with ranges or means with standard deviations. Categorical variables were analysed by the chi-square test or Fisher exact test between 2 groups and linear by linear association between 3 groups, while 
continuous variables were analysed using the Mann-Whitney test or independent $t$ test. Variables with $P<0.05$ in these univariate analyses were considered for backward model selection using multivariate logistic- regression models to identify independent risk factors for in-hospital mortality (adjusted $P<0.05$ ). And personalized maximum likelihood estimation was used to determine whether risk interactions among risk factors included in multiple regression analysis interacted with mortality. SPSS ver. 24.0 (IBM Corp., Armonk, NY, USA) was used for the statistical analyses.

\section{Results}

During the study period, 78 premature neonates with critical CHD were admitted to the neonatal intensive care unit. Tetralogy of Fallot (19.2\%) was the most common critical CHD, followed by pulmonary atresia with VSD (15.4\%) and singleventricle (12.8\%) (Table 1). There was no critical CHD with M-RACHS 1. Nine infants died before intervention (Supplementary Table 1), and one infant with Edward syndrome was discharged without intervention. Sixty-eight patients $(87.2 \%)$ underwent cardiac intervention, and 61 of them (89.7\%) underwent surgery. The mortality rate was the highest in patients with
M-RACHS 6 in the total population and in the subgroup of patients who underwent intervention.

In the total population, the median GA and birth weight were 34.9 weeks and $1.91 \mathrm{~kg}$, respectively. VLBW infants comprised $14.1 \%$ of the study population, and preterm infants who were born at less than 32 weeks comprised $12.8 \%$ of the study population (Supplementary Table 2). There were 18 infants in the mortality group, including 9 patients who died after cardiac intervention, resulting in an overall in-hospital survival rate of $76.9 \%$. Infants with a $\mathrm{GA}<32$ weeks at birth (vs. GA $\geq 32$ weeks, $P=0.001$ ), VLBW, PPHN, BPD, M-RACHS $\geq 5$, and single-ventricle physiology were more prevalent in the mortality group, and the differences between groups were statistically significant. Cardiac intervention was more frequently performed in the survivor group (Table 2). Among the preterm infants with $G A \geq 32$ weeks, there was no statistical difference for the survival according to the birth age $(32 \leq \mathrm{GA}<34$ vs. $34 \leq \mathrm{GA}<37, P=$ $0.103)$. In the mortality group, cause of death were cardiac conditions in 15 patients, sepsis in one patient, pulmonary hemorrhage in one patient and severe BPD in one patient.

Among the 68 infants who underwent cardiac intervention, 9 (13.2\%) died during hospitalization (Table 3). The median GA and birth weight in the subgroup were 34.7 weeks and $1.92 \mathrm{~kg}$, respectively. The PMA and body weight at cardiac intervention

Table 1. Critical congenital heart disease and mortality according to the M-RACHS category

\begin{tabular}{|c|c|c|c|c|c|c|}
\hline \multirow{2}{*}{ Variable } & \multicolumn{3}{|c|}{ Total } & \multicolumn{3}{|c|}{ Intervention } \\
\hline & Patient $(n=78)$ & Death $(n=18)$ & Mortality rate (\%) & Patient (n=68) & Death $(n=9)$ & Mortality rate (\%) \\
\hline M-RACHS 2 & $29(37.2)$ & 2 & 6.9 & $29(42.6)$ & 2 & 6.9 \\
\hline CoA requiring neonatal surgery & $4(5.1)$ & 1 & 25.0 & $4(5.9)$ & 1 & 25.0 \\
\hline TOF & $15(19.2)$ & 0 & 0 & $15(22.0)$ & 0 & 0 \\
\hline DORV & $2(2.6)$ & 1 & 50.0 & $2(2.9)$ & 1 & 50.0 \\
\hline PS with neonatal intervention & $7(9.0)$ & 0 & 0 & $7(10.3)$ & 0 & 0 \\
\hline Aortopulmonary window & $1(1.3)$ & 0 & 0 & $1(1.5)$ & 0 & 0 \\
\hline M-RACHS 3 & $24(30.7)$ & 4 & 16.7 & $21(30.9)$ & 2 & 9.5 \\
\hline TGA without VSD & $3(3.8)$ & 0 & 0 & $3(4.4)$ & 0 & 0 \\
\hline CAVSD & $3(3.8)$ & 2 & 66.7 & $1(1.5)$ & 0 & 0 \\
\hline DORV with CAVSD & $1(1.3)$ & 0 & 0 & $1(1.5)$ & 0 & 0 \\
\hline CoA with VSD & $5(6.4)$ & 0 & 0 & $4(5.9)$ & 0 & 0 \\
\hline PA with VSD & $12(15.4)$ & 2 & 16.7 & $12(17.6)$ & 2 & 16.7 \\
\hline M-RACHS 4 & $6(7.7)$ & 1 & 16.7 & $5(7.4)$ & 0 & 0 \\
\hline AS requiring neonatal surgery & $1(1.3)$ & 0 & 0 & $1(1.5)$ & 0 & 0 \\
\hline Interruption of aortic arch & $1(1.3)$ & 1 & 100 & - & - & - \\
\hline TAPVR & $3(3.8)$ & 0 & 0 & $3(4.4)$ & 0 & 0 \\
\hline Truncus arteriosus & $1(1.3)$ & 0 & 0 & $1(1.5)$ & 0 & 0 \\
\hline M-RACHS 5 & $13(16.7)$ & 5 & 38.5 & $10(14.7)$ & 2 & 20.0 \\
\hline Single-ventricle & $10(12.8)$ & 3 & 30.0 & $8(11.8)$ & 1 & 12.5 \\
\hline Complex CHD with heterotaxy & $3(3.8)$ & 2 & 66.7 & $2(2.9)$ & 1 & 50.0 \\
\hline M-RACHS 6 & $5(6.4)$ & 5 & 100 & $3(4.4)$ & 3 & 100 \\
\hline Hypoplastic left heart syndrome & $5(6.4)$ & 5 & 100 & $3(4.4)$ & 3 & 100 \\
\hline Cardiomyopathy with PS & $1(1.3)$ & 1 & 100 & - & - & - \\
\hline
\end{tabular}

Values are presented as number (\%).

M-RACHS, new modified version of the Risk Adjustment for Congenital Heart Surgery; CoA, coarctation of the aorta; TOF, tetralogy of Fallot; DORV, doubleoutlet right ventricle; PS, pulmonary stenosis; TGA, transposition of the great arteries; VSD, ventricular septal defect; cAVSD, complete atrioventricular septal defect; PA, pulmonary atresia; AS, aortic stenosis; TAPVR, total anomalous pulmonary venous return; CHD, congenital heart disease. 
Table 2. Demographic characteristics of the study population according to in-hospital mortality

\begin{tabular}{|c|c|c|c|c|}
\hline Variable & Total $(n=78)$ & Survivors $(n=60)$ & Nonsurvivors $(\mathrm{n}=18)$ & $P$-value \\
\hline Male sex & $38(48.7)$ & $29(48.3)$ & $9(23.7)$ & 1.000 \\
\hline GA at birth (wk) & $34.9(26.7-36.9)$ & $34.7(27.6-36.9)$ & $35.1(26.7-36.9)$ & 0.533 \\
\hline$<32$ & $10(12.8)$ & $3(5.0)$ & $7(70)$ & 0.214 \\
\hline$\geq 32,<34$ & $14(17.9)$ & $14(23.3)$ & $0(0)$ & \\
\hline$\geq 34,<37$ & $54(69.2)$ & $43(71.7)$ & $11(20.3)$ & \\
\hline Birth weight $(\mathrm{kg})$ & $1.91(0.53-4.38)$ & $1.93(0.53-4.38)$ & $1.80(0.61-3.30)$ & 0.313 \\
\hline Very low birth weight & $11(14.1)$ & $5(8.3)$ & $6(33.3)$ & 0.015 \\
\hline Small for GA & $32(41.0)$ & $24(40.0)$ & $8(44.4)$ & 0.737 \\
\hline Foetal hydrops & $3(3.8)$ & $1(1.7)$ & $2(11.1)$ & 0.131 \\
\hline Outborn & $34(43.6)$ & $28(46.7)$ & $6(33.3)$ & 0.419 \\
\hline PPHN & $4(5.1)$ & $1(1.7)$ & $3(16.7)$ & 0.036 \\
\hline Noncardiac structural anomaly & $14(17.9)$ & $13(21.7)$ & $1(5.6)$ & 0.169 \\
\hline Chromosome anomaly & $7(9.0)$ & $5(8.3)$ & $2(11.1)$ & 0.659 \\
\hline \multicolumn{5}{|l|}{ Morbidity } \\
\hline Sepsis & $1(1.3)$ & $0(0.0)$ & $1(5.6)$ & 0.231 \\
\hline Necrotizing enterocolitis & $6(7.7)$ & $3(5.0)$ & $3(16.7)$ & 0.132 \\
\hline IVH $\geq$ grade II & $3(3.8)$ & $2(3.3)$ & $1(5.6)$ & 0.550 \\
\hline Periventricular leukomalacia & $4(5.1)$ & $2(3.3)$ & $2(11.1)$ & 0.226 \\
\hline Bronchopulmonary dysplasia & $12(15.4)$ & $5(8.3)$ & $7(38.9)$ & 0.005 \\
\hline Retinopathy of prematurity & $2(2.6)$ & $2(3.3)$ & $0(0.0)$ & 1.000 \\
\hline M-RACHS $\geq 5$ & $18(23.1)$ & $8(13.3)$ & $10(58.6)$ & 0.000 \\
\hline Single-ventricle physiology & $15(19.2)$ & $7(11.7)$ & $8(44.4)$ & 0.002 \\
\hline Preintervention PGE1 & $45(57.7)$ & $32(53.3)$ & $13(72.2)$ & 0.155 \\
\hline Heterotaxy syndrome & $5(6.4)$ & $2(3.3)$ & $3(16.7)$ & 0.078 \\
\hline Intervention & 68 (87.2) & 59 (98.3) & $9(50.0)$ & 0.000 \\
\hline
\end{tabular}

Values are presented as number (\%) or median (range).

GA, gestational age; PPHN, persistent pulmonary hypertension of the newborn; IVH, intraventricular hemorrhage; M-RACHS, new modified version of the Risk Adjustment for Congenital Heart Surgery; PGE1, prostaglandin E1.

Boldface indicates a statistically significant difference with $P<0.05$.

were 40.3 weeks and $3.10 \mathrm{~kg}$, respectively. Infants with extremely preterm birth (vs. GA $\geq 32$ weeks, $P=0.001$ ), VLBW, NEC, BPD, M-RACHS $\geq 5$, single-ventricle physiology, and pulmonary artery banding were more prevalent in the mortality group. There were no differences in the timing of intervention in terms of PNA or PMA between survivors and nonsurvivors. Preintervention conditions such as $\mathrm{SpO}_{2}$ and duration of mechanical ventilation were also comparable between the 2 groups. Weight at intervention was lower in the mortality group, with borderline significance.

Multiple logistic-regression analysis in the total population showed that VLBW (adjusted odds ratio [aOR], 7.45; 95\% confidence interval $[\mathrm{CI}], 1.11-50.67 ; P=0.039$ ), PPHN (aOR, 31.57; 95\% CI, 1.64 to 609.28 ; $P=0.022$ ), BPD (aOR, 9.84; 95\% CI, 1.71-56.44; $P=0.010)$, and M-RACHS 5 or greater (aOR, 18.20; 95\% CI, 3.51-94.43; $P=0.001$ ) were independently associated with in-hospital mortality. As a result of personalized maximum likelihood estimation, estimates for interactions between VLBW*PPHN (estimate $-0.981, P=0.720$ ), VLBW*BPD (1.767, $P=0.383)$, VLBW*M-RACHS $\geq 5(-0.295$, $P=0.891)$, PPHN*M-RACHS $\geq 5 \quad(-1.147, P=0.677)$, and BPD*M-RACHS $\geq 5(0.561, P=0.775)$ were not significant in the study population.
In the subgroup with cardiac intervention, multiple logisticregression analysis showed that VLBW (aOR, 23.63; 95\% CI, $1.24-451.06$; $P=0.036$ ), BPD (aOR, 33.07; 95\% CI, 2.49$438.61 ; P=0.008$ ), and M-RACHS 5 or greater (aOR, 51.45 ; 95\% CI, 2.52-1,050.04; $P=0.010$ ) were independently associated with in-hospital mortality (Table 4).

\section{Discussion}

In the present study, the overall in-hospital survival rates were $76.9 \%$ among premature neonates with critical $\mathrm{CHD}$ and $86.8 \%$ among patients with critical CHD who received cardiac intervention, which are comparable to the results of previous studies. A study using the nationwide database of the US reported that the survival to discharge rates were $74.0 \%$ among preterm infants with critical CHD and $81.5 \%$ among patients with critical CHD undergoing surgery. ${ }^{4}$ A study from Children's Hospital Boston reported that the survival rate was $79 \%$ in preterm infants with critical CHD. ${ }^{13)}$

To adjust severity of CHD, M-RACHS was used to adjust during multivariate analysis and VLBW, BPD, and M-RACHS 5 or more were independently associated with in-hospital death 
Table 3. Demographic characteristics of patients receiving cardiac intervention according to in-hospital mortality

\begin{tabular}{|c|c|c|c|c|}
\hline Variable & Total $(n=68)$ & Survivor $(n=59)$ & Nonsurvivors $(n=9)$ & $P$-value \\
\hline Male sex & $35(51.5)$ & $30(50.8)$ & $5(55.6)$ & 1.000 \\
\hline GA at birth (wk) & $34.7(26.7-36.8)$ & $34.7(27.6-36.9)$ & $31.7(26.7-36.1)$ & 0.043 \\
\hline$<32$ & $8(11.8)$ & $3(5.1)$ & $5(55.6)$ & 0.039 \\
\hline$\geq 32,<34$ & $14(20.6)$ & $14(23.7)$ & 0 & \\
\hline$\geq 34,<37$ & $46(67.6)$ & $42(71.2)$ & $4(44.4)$ & \\
\hline Birth weight $(\mathrm{kg})$ & $1.92(0.53-4.38)$ & $1.93(0.53-4.38)$ & $1.73(0.61-3.02)$ & 0.078 \\
\hline Very low birth weight & $9(13.2)$ & $5(8.5)$ & $4(44.4)$ & 0.014 \\
\hline Small for GA & $27(39.7)$ & $23(39.0)$ & $4(44.4)$ & 1.000 \\
\hline Hydrops foetalis & $2(2.9)$ & $1(1.7)$ & $1(11.1)$ & 0.249 \\
\hline Outborn & $30(44.1)$ & $27(45.8)$ & $3(33.3)$ & 0.721 \\
\hline Noncardiac structural anomaly & $13(19.1)$ & $13(22.0)$ & $0(0)$ & 0.189 \\
\hline Chromosome syndrome & $4(5.9)$ & $4(6.8)$ & $0(0)$ & 1.000 \\
\hline \multicolumn{5}{|l|}{ Morbidity } \\
\hline Sepsis & $1(1.5)$ & $0(0)$ & $1(11.1)$ & 0.132 \\
\hline Necrotizing enterocolitis & $6(8.8)$ & $3(5.1)$ & $3(33.3)$ & 0.027 \\
\hline IVH $\geq$ grade II & $2(2.9)$ & $2(3.4)$ & $0(0)$ & 1.000 \\
\hline Periventricular leukomalacia & $4(5.9)$ & $2(3.4)$ & $2(22.2)$ & 0.082 \\
\hline Bronchopulmonary dysplasia & $11(16.2)$ & $5(8.5)$ & $6(66.7)$ & 0.000 \\
\hline Retinopathy of prematurity & $2(2.9)$ & $2(3.4)$ & $0(0)$ & 1.000 \\
\hline $\mathrm{M}-\mathrm{RACHS} \geq 5$ & $13(19.1)$ & $8(13.6)$ & $5(55.6)$ & 0.010 \\
\hline Single-ventricle physiology & $11(16.2)$ & $7(11.9)$ & $4(44.4)$ & 0.032 \\
\hline Preintervention PGE 1 & $39(57.4)$ & $31(52.5)$ & $8(88.9)$ & 0.068 \\
\hline Preintervention $\mathrm{SpO}_{2}(\%)$ & $91.8(57-100)$ & $92(57-100)$ & $87(79.5-94)$ & 0.163 \\
\hline Heterotaxy syndrome & $3(4.4)$ & $2(3.4)$ & $1(11.1)$ & 0.351 \\
\hline Preintervention ventilator period (day) & $5.4 \pm 13.8$ & $3.2 \pm 8.0$ & $19.56 \pm 29.4$ & 0.001 \\
\hline Postnasal age at intervention (day) & $48(1-232)$ & $48(1-232)$ & $57(2-106)$ & 0.581 \\
\hline Postmenstrual age at intervention (wk) & $40.3(31.1-68.6)$ & $40.6(34.7-68.6)$ & $38.0(31.1-46.9)$ & 0.172 \\
\hline Weight at intervention $(\mathrm{kg})$ & $3.10(1.31-7.70)$ & $3.20(1.58-7.70)$ & $2.83(1.31-3.30)$ & 0.066 \\
\hline$<2.5$ & $21(30.9)$ & $17(28.8)$ & $4(44.4)$ & 0.442 \\
\hline Pulmonary artery banding & $6(8.8)$ & $3(5.1)$ & $3(33.3)$ & 0.027 \\
\hline Pulmonary stenosis ballooning & $7(10.3)$ & $7(11.9)$ & $0(0)$ & 0.582 \\
\hline Blalock-Taussig shunt & $15(22.1)$ & $11(18.6)$ & $4(44.4)$ & 0.100 \\
\hline
\end{tabular}

Values are presented as number (\%), median (range), or mean \pm standard deviation.

GA, gestational age; IVH, intraventricular hemorrhage; M-RACHS, new modified version of the Risk Adjustment for Congenital Heart Surgery; PGE1, prostaglandin $\mathrm{E} 1 ; \mathrm{SpO}_{2}$, saturation of peripheral oxygen.

Boldface indicates a statistically significant difference with $P<0.05$.

Table 4. Multivariate logistic-regression analysis for in-hospital mortality in the total study population and the intervention group

\begin{tabular}{|c|c|c|c|c|}
\hline \multirow{2}{*}{ Variable } & \multicolumn{2}{|c|}{ Total $(n=78)$} & \multicolumn{2}{|c|}{ Intervention ( $n=68$ ) } \\
\hline & $\mathrm{aOR}^{\mathrm{a})}(95 \% \mathrm{Cl})$ & $P$-value & $\mathrm{aOR}^{\mathrm{b})}(95 \% \mathrm{Cl})$ & $P$-value \\
\hline VLBW & $7.45(1.11-50.67)$ & 0.039 & $23.63(1.24-451.06)$ & 0.036 \\
\hline PPHN & $31.57(1.64-609.28)$ & 0.022 & & \\
\hline BPD & $9.84(1.71-56.44)$ & 0.010 & 33.07 (2.49-438.61) & 0.008 \\
\hline M-RACHS $\geq 5$ & $18.20(3.51-94.43)$ & 0.001 & $51.45(2.52-1,050.04)$ & 0.010 \\
\hline
\end{tabular}

aOR, adjusted odds ratio; $\mathrm{Cl}$, confidence interval; VBLW, very low birth weight; PPHN, persistent pulmonary hypertension of the newborn; BPD, bronchopulmonary dysplasia; M-RACHS, new modified version of the Risk Adjustment for Congenital Heart Surgery; GA, gestational age; NEC, necrotizing enterocolitis.

${ }^{a}$ Covariate factors included in the logistic-regression models were GA<32 weeks at birth, VLBW, PPHN, BPD, and M-RACHS category $\geq 5$. ${ }^{\text {b) } C o v a r i a t e}$ factors included in the logistic-regression models were GA<32 weeks at birth, VLBW, NEC, BPD, and M-RACHS category $\geq 5$.

Boldface indicates a statistically significant difference with $P<0.05$.

in both the total study population and among those who received intervention. PPHN was an additional risk factor in the total population alone. Several studies have reported the risk of mortality in preterm infants with critical CHD, such as lower
GA, lower birth weight, body weight $<2,500 \mathrm{~g}$ at the time of surgery and RACHS- $1 \geq 4.4,6,13,20)$ However, the risk factors for mortality in this population have been inconsistent among studies so far. 
Steurer et al. ${ }^{6}$ reported that the mortality rates in infants with critical CHD were $41.4 \%$ at a GA $<29$ weeks and $18.5 \%$ at a GA $<35-36$ weeks and decreased to $8.9 \%$ at a GA $39-42$ weeks after adjusting with m-RACHS. On the other hand, Anderson et al. ${ }^{20)}$ reported the importance of birth weight in mortality, showing that the outcomes of mortality in VLBW infants with major CHD were $78.6 \%$ at a birth weight $<750 \mathrm{~g}$ and $50.6 \%$ at a birth weight of $750-999 \mathrm{~g}$, and decreased to $41.4 \%$ at a birth weight of 1,000-1,499 g. In the Kids' Inpatient Database set, ${ }^{4)}$ mortality for neonates born at birth with a body weight $\leq 1,500 \mathrm{~g}$ was also significantly greater in neonates with critical CHD who underwent surgery than in those born at birth with a body weight $>1,500 \mathrm{~g}$, which was consistent among those who did not undergo surgery. In this study, VLBW was a significant risk factor for mortality. Late preterm infants did not have a benefit in survival.

The pivotal strategy in the management of preterm infants with CHD consists of delaying surgical intervention until the newborn is mature due to the small size of cardiovascular structures and immaturity of vital organs. ${ }^{9)}$ Moreover, although a surgical approach for most cases of $\mathrm{CHD}$ is technically feasible, low body weight is still considered a relative contraindication for cardiopulmonary bypass (CPB) and is associated with an increase in CPB-related complications, such as seizures or intraventricular bleeding. ${ }^{9}{ }^{11)}$ Therefore, surgical repair of $\mathrm{CHD}$ in neonates weighing less than $2.5 \mathrm{~kg}$ is challenging, and hospital mortality rates for patients weighing less than $2.5 \mathrm{~kg}$ at the time of cardiac surgery range from $10.4 \%$ to $24 \%$ in various studies, corresponding to a 1.5 to 3.0 fold higher risk of death. ${ }^{10,21-23)}$

However, some studies have reported no association between lower weight at surgery and mortality. ${ }^{19,20)}$ One of the most important factors associated with mortality is the complexity or severity of CHD. ${ }^{4,10,12,13,24)}$ In the Vermont Oxford Network database, ${ }^{12)}$ mortality rates were higher in patients with HLHS and other single-ventricle lesions $(85.2 \%$ and $84.0 \%)$ than in those with tetralogy of Fallot (32.3\%), aortic stenosis treated with balloon valvuloplasty (25.0\%), coarctation of aorta treated with surgical repair (16.4\%), and pulmonic stenosis treated with balloon valvuloplasty (7.4\%). In the Kids' Inpatient Databases cohort, ${ }^{24)}$ the risk of mortality was 3 -fold higher for arch anomalies and greater than 10-fold higher for more complex defects, such as a double-outlet right ventricle, HLHS, non-HLHS single-ventricle, and pulmonary atresia. Several studies have used RACHS- 1 to categorize the severity of CHD and have shown that RACHS-1 4 or greater is an independent predictor of mortality. ${ }^{4,13,24)}$ Our data also demonstrated that the severity of $\mathrm{CHD}$ was an independent risk factor for mortality, showing that M-RACHS 5 or 6 was a significant risk for death even in the multivariate analysis.

In this study, PPHN and BPD were identified as one of the independent risk factors for death among the total population. The prognosis of PPHN in premature infants or in patients with CHD is unfavourable. ${ }^{17,25)}$ The incidence of PPHN in premature infants is higher than that in term infants, and the PPHN- associated mortality rate in premature infants is also higher. ${ }^{25)}$ Recently, pulmonary hypertension in the early neonatal period has been recognized as a pulmonary vascular disease of preterm infants that is associated with BPD, subsequent pulmonary hypertension, and mortality. ${ }^{26)}$ BPD should be recognized as both an important manifestation of critical CHD that requires prolonged use of a ventilator assist device and a cause of mortality representing pulmonary conditions leading to unfavourable outcomes. ${ }^{11,27,28)}$

This is a retrospective study conducted at a single center with a small sample size, and risk factors for long-term outcome were not considered. Although infants with CHD of M-RACHS 5 or 6 had higher mortality than those with M-RACHS 1-4, there was no mortality in infants with M-RACHS 4. Larger study population would be required to validate M-RACHS in preterm infants. However, this is the first study using M-RACHS to demonstrate risk factors of mortality in preterm infants with critical CHD in Korea. Because there are many conditions that don't require intervention during neonatal period, using $\mathrm{M}$ RACHS before surgery would be helpful in predicting prognosis of critical CHD in preterm infants.

In conclusion, VLBW, PPHN, BPD, and M-RACHS 5 or greater were risk factors for mortality in premature infants with critical CHD. PPHN and BPD were important morbidities in premature infants and could worsen the underlying heart disease. These conditions should be managed properly and meticulously, and the timing of intervention should be determined based on the underlying conditions of the preterm infants. Further studies of long-term mortality and morbidities, such as neurodevelopmental outcomes, should be guaranteed.

\section{Conflicts of interest}

No potential conflict of interest relevant to this article was reported.

\section{Acknowledgments}

This research was supported by the Basic Science Research Program through the National Research Foundation of Korea (NRF) funded by the Ministry of Education (NRF-2017R1D1 A1B03036383).

Supplementary materials

Supplementary Tables 1 and 2 can be found via https://doi.org/ 10.3345/cep.2019.01522.

See thc commentary "Risk factors for in-hospital mortality in premature infants with critical congenital heart disease" via https://doi.org/10.3345/cep.2020.00444.

\section{References}

1. Magro Malosso ER, Saccone G, Simonetti B, Squillante M, Berghella V. US trends in abortion and preterm birth. J Matern Fetal Neonatal Med 2018;31:2463-7. 
2. Zeitlin J, Szamotulska K, Drewniak N, Mohangoo AD, Chalmers J, Sakkeus L, et al. Preterm birth time trends in Europe: a study of 19 countries. BJOG 2013;120:1356-65.

3. Honein MA, Kirby RS, Meyer RE, Xing J, Skerrette NI, Yuskiv N, et al. The association between major birth defects and preterm birth. Matern Child Health J 2009;13:164-75.

4. Desai J, Aggarwal S, Lipshultz S, Agarwal P, Yigazu P, Patel R, et al. Surgical interventions in infants born preterm with congenital heart defects: an analysis of the kids' inpatient database. J Pediatr 2017;191:103-9.

5. Oster ME, Lee KA, Honein MA, Riehle-Colarusso T, Shin M, Correa A. Temporal trends in survival among infants with critical congenital heart defects. Pediatrics 2013;131:e1502-8.

6. Steurer MA, Baer RJ, Keller RL, Oltman S, Chambers CD, Norton ME, et al. Gestational age and outcomes in critical congenital heart disease. Pediatrics 2017;140:e20170999.

7. Khoshnood B, De Vigan C, Vodovar V, Goujard J, Lhomme A, Bonnet D, et al. Trends in prenatal diagnosis, pregnancy termination, and perinatal mortality of newborns with congenital heart disease in France, 19832000: a population-based evaluation. Pediatrics 2005;115:95-101.

8. Tanner K, Sabrine N, Wren C. Cardiovascular malformations among preterm infants. Pediatrics 2005;116:e833-8.

9. Natarajan G, Anne SR, Aggarwal S. Outcomes of congenital heart disease in late preterm infants: double jeopardy? Acta Paediatr 2011;100:1104-7.

10. Abrishamchian R, Kanhai D, Zwets E, Nie L, Cardarelli M. Low birth weight or diagnosis, which is a higher risk?: a meta-analysis of observational studies. Eur J Cardiothorac Surg 2006;30:700-5.

11. Axelrod DM, Chock VY, Reddy VM. Management of the preterm infant with congenital heart disease. Clin Perinatol 2016;43:157-71.

12. Archer JM, Yeager SB, Kenny MJ, Soll RF, Horbar JD. Distribution of and mortality from serious congenital heart disease in very low birth weight infants. Pediatrics 2011;127:293-9.

13. Cheng HH, Almodovar MC, Laussen PC, Wypij D, Polito A, Brown DW, et al. Outcomes and risk factors for mortality in premature neonates with critical congenital heart disease. Pediatr Cardiol 2011;32:1139-46.

14. Jenkins KJ, Gauvreau K, Newburger JW, Spray TL, Moller JH, Iezzoni LI. Consensus-based method for risk adjustment for surgery for congenital heart disease. J Thorac Cardiovasc Surg 2002;123:110-8.

15. Centers for Disease Control and Prevention (CDC). Congenital heart defects (CHDs) [Internet]. Atlanta, GA: CDC; 2015 [cited 2018 Jan 8]. Available from: http://www.cdc.gov/ncbddd/heartdefects/data.html.

16. Fenton TR, Kim JH. A systematic review and meta-analysis to revise the Fenton growth chart for preterm infants. BMC Pediatr 2013;13:59.

17. Sallaam S, Natarajan G, Aggarwal S. Persistent pulmonary hypertension of the newborn with D-transposition of the great arteries: management and prognosis. Congenit Heart Dis 2016;11:239-44.
18. Jobe AH, Bancalari E. Bronchopulmonary dysplasia. Am J Respir Crit Care Med 2001;163:1723-9.

19. Bell MJ, Ternberg JL, Feigin RD, Keating JP, Marshall R, Barton L, et al. Neonatal necrotizing enterocolitis: therapeutic decisions based upon clinical staging. Ann Surg 1978;187:1-7.

20. Anderson AW, Smith PB, Corey KM, Hill KD, Zimmerman KO, Clark $\mathrm{RH}$, et al. Clinical outcomes in very low birth weight infants with major congenital heart defects. Early Hum Dev 2014;90:791-5.

21. Ades AM, Dominguez TE, Nicolson SC, Gaynor JW, Spray TL, Wernovsky G, et al. Morbidity and mortality after surgery for congenital cardiac disease in the infant born with low weight. Cardiol Young 2010; 20:8-17.

22. Seo DM, Park JJ, Yun TJ, Kim YH, Ko JK, Park IS, et al. The outcome of open heart surgery for congenital heart disease in infants with low body weight less than 2500 g. Pediatr Cardiol 2011;32:578-84.

23. Curzon CL, Milford-Beland S, Li JS, O'Brien SM, Jacobs JP, Jacobs ML, et al. Cardiac surgery in infants with low birth weight is associated with increased mortality: analysis of the Society of Thoracic Surgeons Congenital Heart Database. J Thorac Cardiovasc Surg 2008;135:546-51.

24. Chu PY, Li JS, Kosinski AS, Hornik CP, Hill KD. congenital heart disease in premature infants 25-32 weeks' gestational age. J Pediatr 2017;181:3741.

25. Roofthooft MT, Elema A, Bergman KA, Berger RM. Patient characteristics in persistent pulmonary hypertension of the newborn. Pulm Med 2011;2011:858154.

26. Mourani PM, Sontag MK, Younoszai A, Miller JI, Kinsella JP, Baker $\mathrm{CD}$, et al. Early pulmonary vascular disease in preterm infants at risk for bronchopulmonary dysplasia. Am J Respir Crit Care Med 2015;191:8795.

27. Mirza H, Ziegler J, Ford S, Padbury J, Tucker R, Laptook A. Pulmonary hypertension in preterm infants: prevalence and association with bronch. opulmonary dysplasia. J Pediatr 2014;165:909-14.

28. Berenz A, Vergales JE, Swanson JR, Sinkin RA. Evidence of early pulmonary hypertension is associated with increased mortality in very low birth weight infants. Am J Perinatol 2017;34:801-7.

How to cite this article: Yoon YM, Bae SP, Kim YJ, Kwak JG, Kim WH, Song MK, et al. New modified version of the Risk Adjustment for Congenital Heart Surgery category and mortality in premature infants with critical congenital heart disease. Clin Exp Pediatr 2020;63:395-401. https://doi.org/10.3345/ cep. 2019.01522 